\title{
Salvaguarda del patrimonio indígena: cuando una piedra es más que un objeto
}

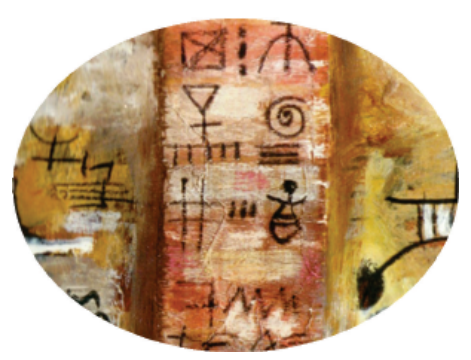

Jenny González Muñoz*

\section{Resumo}

O desconhecimento e desvalorização das culturas indígenas americanas têm traído situações de violação a bens patrimoniais como o traslado a Alemanha em 1998, da pedra Kueka Abuela, pertencente à etnia pemón, da Venezuela, elemento natural que tem uma grande carga simbólica instaurada nos mitos, daí que seja preciso que as políticas públicas tomem conta da importância dessas significações.

Palavras-chave: Culturas indigenas; simbologia; pedra Kueka Abuela; patrimônio.

\section{Abstract}

The ignorance and devaluation of the American Indian cultures have betrayed situations of violation of assets as the transfer to Germany in 1998, the Kueka Abuela stone, belonging to ethnic Pemón Venezuela's natural element that has a great symbolic established myths, there it is necessary that public policies take account of the importance of this meaning.

\footnotetext{
Doctora en Cultura Latinoamericana y del Caribe Instituto Pedagógico de Caracas- Universidad Pedagógica Experimental Libertador - Venezuela. Mestranda en Memoria Social y Patrimonio Cultural Universidad Federal de Pelotas - Brasil. E-mail: jenny.planificacion@gmail.com
} 
Keywords: Ancestral cultures; symbols; Kueka Abuela stone; heritage.

\section{Introducción}

Desde tiempos remotos las culturas de los diversos pueblos indígenas se han desarrollado en las llamadas por los colonizadores europeos, tierras americanas, factor que le imprime al continente todo características bastantes diferenciadas que conviven con otras culturas de índole occidentalizado, lo cual ha dado pie para el desarrollo de perspectivas signadas desde la óptica eurocentrista que pretenden minimizar la significación simbólica de elementos importantes para los pueblos ancestrales, tales como el territorio y sus manifestaciones culturales. En este sentido, el rol de la declaratoria de patrimonio debe ser tomado desde la instauración de políticas públicas cónsonas con el respeto, valoración y salvaguarda de los componentes de las culturas originarias, tal es el caso de la Kueka Abuela, piedra perteneciente a la cosmovisión pemón de alta carga simbólica, la cual fue extraída de su territorialidad por causa del desconocimiento y la ignorancia sobre la cultura de dicho pueblo indígena.

\section{Territorialidades indígenas: más allá de los mitos}

Los antiguos incas llamaban Tawantinsuyu a la extensión de tierras que conformaban su reino, siendo esas "cuatros partes del mundo" que se desplegaban hacia los cuatro puntos cardinales, mucho más que miles de kilómetros que permitirían designar la supremacía de los hijos de sol como la más vasta del continente; la cosmovisión inca imprimía ya desde los mitos que hablaban de Manco Cápac y Mama Ocllo como los primigenios, la importancia de la tierra como territorialidad, es decir, como una posesión material cuyo valor simbólico era significativo, característica que sería atribuible a todos los demás pueblos indígenas que conformaban las tierras designadas como América por los colonizadores europeos. Así, entre otras tantas concepciones, el

14 Somanlu, ano 11, n. 1, jan./jun. 2011 
Abya Yala, designación karibe-kuna que puede traducirse como "continente en expansión”, tomada de dichas naciones originarias ubicadas en las actuales Panamá y Colombia se torna una terminología aceptada contemporáneamente a nivel colectivo, con semejante carga simbólica.

La existencia de pueblos indígenas hace de América Latina un continente con características bastante peculiares que, unidas a los procesos de transformación devenidos a partir de la conquista europea de 1492, reclaman políticas públicas diferenciadas y puntuales que, inevitablemente, deben ajustarse a las múltiples visiones de la pluriculturalidad. Muchos de estos pueblos tienen deudas históricas sin resolver las cuales se van incrementando con el pasar del tiempo y la ausencia de soluciones reales en lo que se refiere a su invisibilización, discriminación, así como otros factores que se van desarrollando a la luz de los sistemas sociales, económicos, políticos, entre otros tantos. En este sentido, componentes como la resistencia indígena con sus altos y sus bajos, pueden tener resultados en la medida en que se realice un trabajo endógeno de reconocimiento y valoración, Franz Tamayo ${ }^{2}$ decía que una de las formas de resistencia más importantes de los indígenas bolivianos era la que se hacía mediante la educación, al negarse a aprender la lengua y otras enseñanzas de los blancos, esto obedecía a obstaculizar una posible ruptura de su identidad cultural que, como ya sabemos, tiene fuerte raigambre en la conservación de las tradiciones y el idioma originario. Evidentemente, lo acotado por Tamayo a mediados del siglo XX no se puede aplicar drásticamente en los momentos actuales del siglo XXI cuando el crecimiento vertiginoso de nuevas tecnologías obliga a los pueblos a conocerlas para poder utilizarlas como herramientas de sus procesos reivindicativos.

Las problemáticas en cuanto a las tierras indígenas vienen teniendo presencia desde hace mucho tiempo, ya no hablemos del siglo XV, cuando fueron saqueadas y robadas, sino durante el siglo XX y lo que va del XXI, siendo envueltos cantidad de pueblos que están en franca lucha por la reconstitución de sus áreas ancestrales y en pie de resistencia frente al robo de tierras que aún continua en vigencia, nos arriesgaríamos a decir, en todos los países de América Latina, porque dichas tierras son ricas en diversidad de 
materiales naturales que revisten aumento en la economía de los países, sobre todo aquellos que tienen las riendas de las fracciones imperialistas, como otrora, desde el siglo XV.

Pero resulta que el tratamiento de los pueblos originarios de la tierra se sitúa frente a la territorialidad, teniendo diferentes connotaciones, lo cual implica una visión totalmente distante a la de las culturas occidentalizadas.

\footnotetext{
El territorio para los pueblos indígenas implica un referente de identidad como auto-construcción y auto-reconocimiento comunal, es un espacio que sintetiza elementos vinculados con un pasado común, es decir, histórico, una cosmovisión y un lugar donde se producen todas las relaciones sociales esenciales para una continuidad cultural inscrita en una serie amplia de derechos y deberes colectivos (GONZÁLEZ M., 2009, p. 20).
}

Los indígenas son eminentemente pueblos que se auto-observan y se auto-interpretan como un colectivo, la individualidad está apartada de su cosmovisión, no se conciben desde la perspectiva egocéntrica occidental, de hecho en muchos de sus idiomas el singular y el plural se designan bajo la misma forma, así tampoco es lícito para ellos hablar de "espacios vacíos", puesto que en cada lugar existe la presencia de algo: el aire está allí, un insecto, una planta, una piedra, un espíritu, todo lo cual tiene una significación simbólica. Frente a esto se sitúa la posición de otras culturas que pretenden observar a las indígenas desde su propio reflejo, lo cual, como ya sucedió en la época de la colonización ${ }^{3}$, siempre trae consigo enfrentamientos donde termina siendo víctima el sector menos favorecido, obviamente, el indígena.

Los pueblos occidentalizados no asumen la concepción de la territorialidad, lo que conlleva a que sólo vean en la tierra un lote capitalizable con valor monetario, meramente material, siendo negados de continuo los bienes sagrados de la cosmovisión indígena, de modo que a la hora de mutilar territorios, violentar lugares venerados, trasplantar comunidades, no toman en cuenta la transgresión cultural que están cometiendo. Esta situación se debe a varios factores, por un lado está la ignorancia, el desconocimiento hacia la cultura del "otro" que no va acompañada de un mínimo sentido de

16 Somanlu, ano 11, n. 1, jan./jun. 2011 
comprensión que ayude a un posible acercamiento y la consecuente horizontalidad que lleva al diálogo intercultural, siendo la típica actitud de la cultura que se posiciona sobre la "otra" para verla desde encima, como superior, minimizando de este modo, la calidad y capacidad de la diferencia, Tzvetan Todorov ejemplifica esta situación con la actitud de Cristóbal Colón y sus compañeros de aventura, frente a las culturas originarias que encuentra en América:

[...] pero entonces no solo los ve iguales, sino idénticos, y esta conducta desemboca en el asimilacionismo, en la proyección de los propios valores en los demás. Por otro lado, parte de la diferencia; pero ésta se traduce inmediatamente en términos de superioridad e inferioridad (en su caso, evidentemente, los inferiores son los indios): se niega la existencia de una sustancia humana, realmente otra, que pueda no ser un simple estado imperfecto de uno mismo. Estas dos figuras elementales de la experiencia de la alteridad descansan ambas en el egocentrismo, en la identificación de los propios valores con los valores en general, del propio yo con el universo; en la convicción de que el mundo es uno (TODOROV, 2003, p. 55 - 56).

Cuando los actores culturales proyectan sus propios valores en los demás, tal como acota Todorov, de inmediato se establece el otro factor, que es la relación de superioridad-inferioridad que ya, contemporáneamente no niega la "sustancia humana" de los indígenas, pero que si borra la importancia de sus concepciones por ser diferentes y en este sentido, pretende anular que un determinado territorio (y lo que está dentro de él) tenga una significación cosmogónica, sagrada, que también incluye al ser humano como parte sustancial, así, por ejemplo, el 29 de agosto de 1533, no sólo es asesinado por los españoles Atahuallpa, el último rey inca, su muerte simboliza asimismo la destrucción del imperio.

Los pueblos ancestrales cuentan sus orígenes desde los mitos, manifestándose éstos en la configuración de un sistema de creencias que se va transformando en el correr de los tiempos, teniéndose que acoplar, incluso, a imposiciones religiosas externas. En la tradición oral, devenida de generación 
en generación, como una herencia transmitida de padres a hijos, la mitología explica el por qué y para qué de todas las cosas que están sobre la tierra, teniendo tiempos, espacios, trascendentes, y una funcionalidad moralizadora.

El mito cuenta una historia sagrada; relata un acontecimiento que ha tenido lugar en el tiempo primordial, el tiempo fabuloso de los 'comienzos'. Dicho de otro modo; el mito cuenta cómo, gracias a las hazañas de los Seres Sobrenaturales, una realidad ha venido de la existencia, sea ésta la realidad total, el Cosmos, o solamente un fragmento: una institución (ELIADE, 1985, p. 12).

Lo creado por los seres superiores tiene una existencia comprobable porque se manifiesta en cada elemento de la naturaleza, el sol está ahí para probar que el mito sobre su creación es real, lo mismo acontece con la luna, los ríos, las montañas, los animales, las personas, en fin, cada elemento tiene una razón de ser desde la óptica mítica de los pueblos ancestrales, de allí el sentido sagrado de la naturaleza, con la cual tienen una relación de respeto y valoración que toma cuerpo en la capacidad armónica que se despliega en actos que pudieran tener connotaciones depredadoras como la caza, la pesca y la tala de árboles. En la cosmovisión ancestral todo tiene una razón de ser signada desde el mito, equilibrio que al ser violentado puede traer consigo consecuencias que no sólo abarcan al pueblo como especificidad, sino que es susceptible a otras culturas, incluso las más lejanas, porque es precisamente la razón moralizante del mito la que explica qué no debemos hacer para no tener tales castigos: la tumba de Tutankamón no debía ser profanada so riesgo de muerte de aquellos que la deshonraren; las momias incas deberían ser escondidas para evitar ser violentadas y así llegaran años de epidemias; las piedras sagradas de los pemón no deben ser removidas para impedir desastres naturales. El mito de origen indica una lección porque tiene un carácter re-interpretativo que se va adaptando a las nuevas épocas ya que narra y justifica una situación nueva en el sentido de que no estaba desde el comienzo del mundo, el ultraje a los designios divinos no tiene justificación, ni siquiera si se ignora su existencia, sino que lleva al colectivo a crear una serie de manifestaciones relacionadas con su aprendizaje social (cultura) concentradas en la búsqueda

18 Somanlu, ano 11, n. 1, jan./jun. 2011 
de una conciliación con esa especie de destino irrefutable dictado por el oráculo, y que se ha visto inscrito en las incontables narraciones que cuentan los mitos, de suerte que ceremonias y rituales son elementos que vehiculizan la remisión de los designios celestiales.

\section{Profanación del patrimonio: desconocimiento y desvalorización de la sacralidad}

El paisaje es imprescindible para la configuración de las culturas, así es preciso captar la estructura cosmogónica de la naturaleza, pues ella nos abre el camino para entenderlo también como un constructo cultural en el que tiene lugar un sistema de creencias, simbologías, mitos y ritos que se desarrollan desde el ser humano como creador de la cultura, así expresa Sandra Siveiro que "el modo de vinculación con el paisaje es también una respuesta cultural. Hay una gran diferencia entre apreciarlo desde un lugar de espectador, sin una real conexión, o entenderse y verse como un componente más del mismo." (2009, p. 78) De allí la diferencia fundamental entre la concepción de los elementos que conforman la naturaleza de los pueblos originarios y aquellos de índole occidental que, como ya vimos en el aparte anterior, le dan un sentido eminentemente utilitario, en el cual no existe una horizontalidad armónica alejada de la mera explotación, hecho que es negado por cantidad de miembros quienes no creen en la disminución de la capacidad del planeta para sustentarse ante la contaminación y demás trasgresiones, apagando, de igual modo, la importancia de las culturas originarias respecto a sus sistemas de fe.

Frente a este panorama, organismos como la Organización de las Naciones Unidas para la Educación, la Ciencia y la Cultura (Unesco), se han abocado a establecer mecanismos para el reconocimiento y consecuente salvaguarda de los bienes culturales y naturales por medio de las declaratorias de patrimonio, en sus diversas áreas, ya que éste no es uno sólo, pues está desde el digital, genético, inmaterial, material, industrial, emergente, comunitario, de la humanidad, hasta el cultural, natural, histórico, artístico y familiar (CHAGAS, 2005), entre otros tantos que van naciendo producto de las necesidades 
sociales, políticas y económicas. De manera que, según el organismo internacional, el patrimonio cultural "no se limita a monumentos y colecciones de objetos, sino que comprende también tradiciones o expresiones vivas heredadas de nuestros antepasados y transmitidas a nuestros descendientes"4, lo cual le da una relevancia a las manifestaciones que tienen carácter simbólico. No obstante, la aseveración patrimonio tiene connotaciones un tanto ambiguas, quizá devenidas de la amplitud de lo que pretende designar.

\begin{abstract}
A palavra patrimônio é, ainda hoje, a capacidade de expressar uma totalidade difusa, à semelhança do que ocorre com outros termos como cultura, memória e imaginário. Frequentemente, aqueles que desejam alguma precisão se veem forcados a definir e redefinir o termo. A necessidade de recuperar sua capacidade operacional, driblando seu acento de difusa totalidade, está na raiz das constantes requalificações a que essa palavra tem sido submetida. Se tradicionalmente ela foi utilizada como uma referência a "herança paterna" ou aos "bens familiares" transmitidos de pais (e mães) para filhos (e filhas), em particular no que se referia aos bens de valor econômico e afetivo, ao longo do tempo gradualmente adquiriu novos contornos e ganhou outras qualidades semânticas, sem prejuízo do domínio original (CHAGAS, 2005, p. 115).
\end{abstract}

Siendo que la cultura es todo lo que realiza el ser humano social ya que es su propia invención, el término patrimonio es la normatización de esas manifestaciones culturales, implementada socialmente ya que se precisa de una organización a través de leyes para poder desplegar mecanismos de detección, documentación, registro, archivo, para una posterior declaración que lleve a la protección y salvaguarda, siendo éstas el último eslabón de esta gran cadena. Sin embargo, esto en el papel se ve excelente, pero no ocurre así en la práctica real, quizá porque frente a los bienes patrimoniales de las culturas indígenas se continúe utilizando ópticas "identitarias" y lejanas, que no permiten abrir vías múltiples hacia su conocimiento, respeto y estimación, independientemente si se esté de acuerdo o no con sus prácticas.

Cuentan los antiguos pemón ${ }^{5}$ (pueblo indígena ubicado en la Gran Sabana de Venezuela, y parte de Brasil y Guayana Inglesa) ${ }^{6}$, en el mito recopilado por

20 Somanlu, ano 11, n. 1, jan./jun. 2011 
Fray Cesáreo de Armellada llamado "Las piedras de la caza y de la pesca", que:

\begin{abstract}
Las piedras que atraen la caza y la pesca, las inventaron los Makunaimas. Al reventar, la Vieja-Sapo dentro del fuego que ellos habían prendido alrededor del conuco en que ella estaba prendiendo en vano porque le habían dado unas astillas de krichódek (un árbol que no hace candela), ellos le maldijeron sus ojos para que estallaran y se convirtieran en piedras de los animales de caza y de los pescadores, las que cayeran en los ríos.

De entonces para ać, los descendientes de los Makunaimas creen en la fuerza atractiva de esas piedras y además han logrado hacer algunas nuevas.

[...] Entonces los venados les juegan bromas a los cazadores. Cuando los matan, les tapan la boca para que lancen su trémulo balar; y entonces sí se petrifican para ellos, se hacen piedras.

Cuando hay una piedra de venados en algún lugar de la sabana, luego nos damos cuenta; alrededor de ella se ven las pisadas, pues vienen a lamerla porque es su piedra” (ARMELLADA, 1988, p. 43-44).
\end{abstract}

Dice Armellada en las notas explicativas de dicho mito que:

Es idea corriente entre los indios pemones, que proviene de la famosa leyenda de los Makunaimas, la existencia de piedras especiales, que atraen a los animales de caza y a los pescados. La atractiva para los pescados, aparece denominada “arapué”. De este nombre, alterado fonéticamente, era el antiguo caserío de Arabopó cercano al Roraimá, ya desaparecido (Ibidem, p. 44).

Más delante agrega: "Estas piedras vienen a ser como un cebo y lugar seguro para conseguir caza o pesca. De ahí que los indios celen esas piedras. Su robo o traslado ha sido motivo de graves peleas entre los indios y de grave enojo de los Mawaritón y de los Rató" (Ibidem, p. 44).

En 1998 es extraída la piedra Kueka Abuela ubicada dentro del Parque Nacional Canaima, estado Bolívar, Venezuela, elemento natural que forma parte de la mitología pemón, quienes

Al percatarse de su ausencia, los pemones la interceptaron cuando estaba siendo transportada, por lo que la roca permaneció en el 
comando de la $\mathrm{GN}^{7}$, destacamento 85 de San Isidro, en el kilómetro 88 de la carretera hacia Brasil hasta diciembre de 1998, cuando fue trasladada rumbo a Alemania a pesar de las protestas de distintas organizaciones..." (DELGADO, 2000, s/p).

En ese entonces la comunidad pemón de Santa Cruz de Mapaurí, municipio Santa Elena de Uairén de la Gran Sabana, permanece dos meses en la vía tratando de evitar el traslado de la piedra sagrada a Alemania, ya que según consta en lo transcrito en el memorando de la Consultoría Jurídica de Inparques, de fecha 7 de junio de 2010:

En fecha 8 de junio de 1998, el ciudadano Wolfwang Schwarzenfeld, promotor del proyecto "Global Stone" (Piedras del Mundo), el cual consistía en la búsqueda y recolección de material geológico representativo de cada uno de los continentes, con el objetivo de agruparlos de forma geométrica y lograr una reflexión solar, presentó al entonces Director General del Instituto Nacional de Parques, ciudadano José Francisco Acosta, la solicitud de una autorización para retirar una roca de arenisca, tipo Roraima, de aproximadamente treinta (30) toneladas del Parque Nacional Canaima, perteneciente al pueblo Pemón, cuyo nombre según el pueblo indígena es "Kueka Abuela”...

En diciembre de ese mismo año en Venezuela ocurre una terrible inundación producto de lluvias continuas en el estado costero de Vargas, que cobra gran cantidad de vidas y pérdidas materiales incalculables, los pemón atribuyen a la usurpación de la piedra la responsabilidad de la catástrofe, en cumplimiento fiel de las profecías. Esta situación de traslado de la piedra, de entregarla a otras manos, es producto de la ignorancia a la cultura indígena y del irrespeto a las leyes que regularizan la condición de salvaguarda de los bienes patrimoniales, ya que el Parque Nacional Canaima ha sido declarado por la Unesco como Patrimonio Natural de la Humanidad desde 1994, y por tanto está prohibida toda clase de extracción de elementos que se encuentren dentro de él. En este hecho es factor determinante la importancia simbólica de la piedra Kueka Abuela lo que la convierte en un bien cultural de múltiples aristas: natural y expresión de la cultura tanto material como inmaterial, de

22 Somanlu, ano 11, n. 1, jan./jun. 2011 
modo que el desconocimiento de la cultura del "otro", por suponerla "inferior” (no fueron escuchados los pemón), conllevó a que la Kueka Abuela (Sapo Kuê) fuera considerada desde la visión occidental una piedra más del parque, la condición de bien patrimonial fue desatendida (calidad de donación de la piedra para el gobierno alemán), catapultando una vez más, parte de la memoria colectiva originaria americana.

Siendo colocada como parte de la instalación Global Stone, que pretende reunir piedras representativas de todos los países del mundo como una muestra de unión internacional, Kueka Abuela se encuentra desde 1998 en el Parque Tierganten (Berlín); luego de haber sido intervenida por el artista, tal como acotan los pemón, "la abuela ha sido violada", pero el clamor por su regreso está latente. En este caso es interesante que parte del texto de la Consultoría de Parques Nacionales, de Venezuela, de fecha 07 de junio de 2010, destaque lo grave de la remoción de la piedra ya que 'La extracción del jaspe es una actividad prohibida en los Parques Nacionales"8 de lo que podemos inferir que aún no se está reconociendo la importancia simbólica de la pieza, sino su valor comercial. De igual manera, el Instituto de Patrimonio Cultural, en oficio de fecha 13 de abril de 2011, dirigido al Ministro de Relaciones Exteriores de Venezuela, le solicita gestionar ante el gobierno alemán todo lo relativo a la protocolización de la repatriación de la piedra, expresando lo siguiente:

(...) tomando en cuenta el valor político, histórico y cultural de este hecho, por cuanto sería el reconocimiento y reivindicación de nuestros indígenas y la cultura de nuestro pueblo, en el marco del Bicentenario. Además este hecho podría ser fundamental para la conmoración del día de la Resistencia Indígena, como un acto de reivindicación a nuestro pueblo y a nuestra soberanía.

Desestimando nuevamente el sentimiento pemón, pues la relevancia del regreso de la piedra está colocada en la parte mediática que obedece a una efeméride que en nada pertenece a la cosmovisión indígena, las conmemoraciones son lo que Pierre Nora llama "lugares de memoria", instaurados desde las ópticas oficiales de corte occidental para inventar 
reivindicaciones memoriales que realmente, en estos casos particulares necesitarían, a nuestro parecer, de un trabajo constante los 365 días de todos los años, las banderas, los cantos, los actos culturales donde los pueblos indígenas se siguen tomando como piezas coleccionables para ser observadas en una descontextualización donde el espectador no es más que otro agente externo, minimizan aún más la posibilidad de los propios indígenas de reconocerse en su identidad dejando a un lado las ya hartas posiciones de la victimización. Actualmente en 2012, se está gestionando, una vez más, la repatriación de la Kueka Abuela, un gran paso que ojalá permita solidificar el camino para el respeto de las culturas originarias de América Latina como bienes patrimoniales por su significación espiritual.

\section{Epílogo o la Abuela ha sido violada y ¿ahora qué?}

A catorce años de la extracción y traslado de la piedra sagrada Kueka Abuela a tierras ajenas, los indígenas pemón aun reclaman para que sea devuelta a los territorios ancestrales de Canaima, donde no solo pertenece por ser éste un Parque Nacional y Patrimonio Natural de la Humanidad, sino porque es parte constituyente de la simbología indígena como madre tutelar de distintos designios focalizados en el bienestar de la naturaleza proporcionando una armonía que se ha visto convulsionada en Venezuela desde su desarraigo y consecuente ausencia física. La Abuela Kueka ha sido violada con el pincel, la mano, la máquina de pulir, la pintura, pero a pesar de las miradas extranjeras que solo la ven como una pieza más de las tantas de una exposición europea, se sabe querida por su pueblo desde el mito que la cobija y el rito que la espera de vuelta para devolverle parte de la vida que le queda. Entretanto, cada piache $^{8}$ desde la selva intrincada de la amazonia entona cantos y baila danzas ceremoniales implorando que ahora si, de verdad y para siempre, la piedra sagrada pueda ser posada en el lugar de donde jamás debió extraerse, pero esos cantos y danzas también los hace el piache pidiendo a los ancestros por la salvación y respeto de la cultura pemón, para que sus voces sean escuchadas más allá de las meras apariencias.

24 Somanlu, ano 11, n. 1, jan./jun. 2011 


\section{Notas}

${ }^{1}$ El escritor boliviano Franz Tamayo, en su texto Creación de la pedagogía nacional, habla de cómo la pedagogía a lo largo de su despliegue en América ha masacrado no solo la cultura indígena sino la inteligencia y la "raza", catalogándolas como inferiores frente a la superioridad de la Europea, en este sentido, expresa sus puntos de vista en relación al tratamiento de la historia para los pueblos indígenas bolivianos y su repercusión en las sociedades ancestrales, donde, entre otras cosas acota la importancia de la lengua como forma de resistencia. Para mayor información se sugiere consultar el libro TAMAYO, Franz. Obra escogida. Caracas: Biblioteca Ayacucho, s/ f. (Colección Clásica, n. 62)

${ }^{2}$ Esto es referido por Cristóbal Colón en sus Diarios de Viaje, al describir a los indígenas, sus tradiciones, modos de vida y demás características, desde la óptica europea, colocándolos, por ende, como inferiores. Para ampliar más dicha acotación se sugiere consultar el libro CASAS, Fray Bartolomé de las. Vida de Cristóbal Colón. Caracas: Biblioteca Ayacucho, 1992 (Colección Claves de América, n. 7)

${ }^{3}$ La Unesco en su página Web, responde la interrogante ¿Qué es el patrimonio cultural inmaterial?, haciendo esta aclaratoria, que lo amplia ya no circunscribiendo el patrimonio cultural a lo meramente material, dándole relevancia a las tradiciones, mitos, ritos, costumbres, lo que fuera establecido en el siglo XX como manifestaciones de la cultura "intangible", término cambiado por "inmaterial" ya que estos bienes aunque no son palpables al tacto, son perceptibles con otros sentidos, lo cual da características tangibles.

${ }^{4}$ Se ha de resaltar que la utilización del plural para designar a los pueblos indígenas de Venezuela se realiza como en singular, sea masculino o femenino, y siempre en minúscula, así quedará, en este caso, la designación pemón, en todo sentido. Esto se debe a que dichas lenguas construyen el plural de manera diferente. Durante el siglo XX, e incluso antes, se construía el plural como en español, de allí la utilización por algunos autores.

${ }^{5}$ Fray Cesáreo de Armellada aclara respecto a los pemón que: "Nunca se autodenominaron sabaneros ni denominaron Gran Sabana la tierra que habitaban. Ellos se nombraban pemones, por sus casas de bajareque, de base circular y techo cónico, rodeadas de empalizadas (...); su tierra era wektá (lugar de los cerros y los más salientes de ellos, tepuyes). Gran Sabana (Remonotâ) eran los campos brasileros de Rio Branco (ahora T. Roraima)” (1988, p. 16)

${ }^{6}$ Guardia Nacional.

${ }^{7}$ Informe sobre la Piedra Kueka de 30 abril 2012, Instituto de Patrimonio Cultural.

${ }^{8}$ Shamán, sacerdote. 


\section{Referências}

ARMELLADA, Fray Cesáreo de. Cuentos y no cuentos. Pantón, Pantón Neke-ré. Caracas: Universidad Católica Andrés Bello, 1988.

CHAGAS, Mario. Casas e portas da memória e do patrimônio. IN: GONDAR, Jô; DODEBEI, Vera. O que é a memória? Rio de Janeiro: Contra Capa Livraria, 2005, p. 115-132. INFORME SOBRE LA PIEDRA KUEKA. Disponible en: <www.ipc.gob.ve/informe> Acceso en: 10 jun. 2012.

DELGADO, Claudia. La superficie de jaspe ha sido dañada. La piedra sagrada pemón se encuentra en total abandono en Berlín. Diario El Nacional, Caracas, c/3, 18 julio 2000 .

ELIADE, Mircea. Mito y realidad. Barcelona: Labor, 1985.

GONZÁLEZ MUÑOZ, Jenny. Los espacios posibles: tierra y territorialidad de los pueblos indígenas del Abya Yala. A plena voz, Caracas, n. 57-58, p. 1923, 2009.

PATRIMONIO CULTURAL. Disponible en: www.unesco.org.com

SIVEIRO, Sandra. Antropología. Pueblos. Paisaje. Cuadernos del Centro de Estudios en Diseño y Comunicación, Buenos Aires, n. 30, p. 77-89, 2009.

TODOROV, Tzvetan. La conquista de América: el problema del otro. Buenos Aires: Siglo veintiuno, 2003. 